\title{
Nem todo abscesso em pequenos ruminantes é causado por Corynebacterium pseudotuberculosis ${ }^{1}$
}

\author{
Reanne M.M. Silva ${ }^{2}$, Robson B. Cerqueira ${ }^{3}$, Vinicius P. Vieira ${ }^{3}$, Jorge R.L. Ribas ${ }^{4}$, \\ Karla A. Nascimento ${ }^{5}$, Luciano A. Pimentel ${ }^{2}$, Pedro Miguel O. Pedroso ${ }^{5}$ \\ e Juliana T.S.A. Macêdo ${ }^{5 *}$
}

\begin{abstract}
Silva R.M.M., Cerqueira R.B., Vieira V.P., Ribas J.R.L., Nascimento K.A., Pimentel L.A., Pedroso P.M.O. \& Macêdo J.T.S.A. 2018. [Not all abscesses in small ruminants are caused by Corynebacterium pseudotuberculosis.] Nem todo abscesso em pequenos ruminantes é causado por Corynebacterium pseudotuberculosis. Pesquisa Veterinária Brasileira 38(10):1902-1908. Laboratório de Patologia Veterinária, Universidade de Brasília, Campus Universitário Darcy Ribeiro, Via L4 Norte s/n, Brasília, DF 70910-970, Brazil. E-mail: jtsam_targino@yahoo.com.br

The study aimed to determine the prevalence and distribution of abscessed lesions, etiologic agent identification and assessment of histological lesions in sheep and goats slaughtered in a slaughter plant refrigerator with Federal Inspection Service in the State of Bahia. The amount of 153 samples of viscera and lymph nodes with abscesses of 1.148 slaughtered animals were collected. The highest prevalence in sheep was in males, aged 12 months, as in liver (21.2\%) and prescapular lymph nodes (20.3\%) the main affected organs. The prevalence in goats in male, aged 30 months and in retropharyngeal (25\%) and prescapular lymph nodes (25\%). The following microorganisms were isolated from the samples: Corynebacterium pseudotuberculosis 33.33\%, Escherichia coli 19.61\%, Proteus mirabilis $9.80 \%$, Pseudomonas aeruginosa 7.19\%, Trueperella pyogenes 5.22\%, Streptococcus spp. 5.22\% and Staphylococcus aureus 4.57\%. The macroscopic and histological lesions of abscesses collected presented no difference between isolated microorganisms.
\end{abstract}

INDEX TERMS: Abscesses, sheep, goats, lymph nodes, Corynebacterium pseudotuberculosis, pathology.

RESUMO.- 0 presente estudo objetivou determinar a prevalência e distribuição de lesões abscedativas, identificação do agente etiológico e avaliação das lesões histológicas em caprinos e ovinos abatidos em um matadouro-frigorífico com Serviço de Inspeção Federal do estado da Bahia. Foram coletadas 153 amostras de vísceras e linfonodos com abscessos de

\footnotetext{
${ }^{1}$ Recebido em 9 de janeiro de 2018.

Aceito para publicação em 27 de abril de 2018.

Parte da Dissertação de Mestrado do primeiro autor, Programa de Pós-Graduação em Defesa Agropecuária, Universidade Federal do Recôncavo da Bahia.

${ }^{2}$ Setor de Patologia Veterinária, Universidade Federal do Recôncavo da Bahia (Unfba), Campus Universitário, Rua Rui Barbosa 710, Cruz das Almas, BA 44380-000, Brasil.

${ }^{3}$ Laboratório de Doenças Infecciosas, Universidade Federal do Recôncavo da Bahia (Unfba), Campus Universitário, Rua Rui Barbosa 710, Cruz das Almas, BA 44380-000.

${ }^{4}$ Laboratório de Sanidade Animal, Agência Estadual de Defesa Agropecuária da Bahia, Av. Adhemar de Barros 967, Salvador, BA 44170-110, Brasil.

${ }^{5}$ Laboratório de Patologia Veterinária, Universidade de Brasília, Campus Universitário Darcy Ribeiro, Via L4 Norte s/n, Brasília, DF 70910-970, Brasil. *Autor para correspondência: jtsam_targino@yahoo.com.br
}

1.148 animais abatidos. A maior prevalência na espécie ovina foi em macho, com faixa etária de 12 meses, sendo os principais órgãos acometidos fígado $(21,2 \%)$ e linfonodo pré-escapular $(20,3 \%)$. Na espécie caprina, a prevalência maior foi em macho, com faixa etária de 30 meses, sendo os linfonodos retro faríngeo (25\%) e pré-escapular os mais acometidos (25\%). Isolou-se os seguintes micro-organismos das amostras: Corynebacterium pseudotuberculosis em $33,33 \%$, Escherichia coli $(19,61 \%)$, Proteus mirabilis $(9,80 \%)$, Pseudomonas aeruginosa $(7,19 \%)$, Trueperella pyogenes $(5,22 \%)$, Streptococcus spp. (5,22\%) e Staphylococcus aureus $(4,57 \%)$. As lesões macroscópicas e histológicas dos abscessos coletados não apresentaram diferenças entre micro-organismos isolados.

TERMOS DE INDEXAÇ̃̃O: Abscessos, ovinos, caprinos, linfonodos, Corynebacterium pseudotuberculosis, patologia.

\section{INTRODUÇÃO}

A ovinocultura e caprinocultura brasileira é detentora de um grande rebanho, onde predomina sistema extensivo de manejo, formado por caprinos e ovinos sem raça definida ou nativa 
(Santos 2001). Contudo, a exploração é deficiente quanto ao manejo sanitário e alimentar, por isso a produtividade é prejudicada (Gouveia 2003). As doenças infectocontagiosas, principalmente a linfadenite caseosa (LC), causam prejuízos na produção de pequenos ruminantes.

A LC é uma doença crônica, causada pela bactéria Corynebacterium pseudotuberculosis considerado o principal agente responsável por lesões abscedativas (Unanian et al. 1985, Rosa et al. 1989, Guedes et al. 2007, Abreu et al. 2008, Ribeiro et al. 2011, Souza et al. 2011, Andrade et al. 2012, Valençoela et al. 2012, Higino et al. 2013), porém outras bactérias podem ser a causa dos abscessos, como Staphylococcus aureus, Escherichia coli, Streptococcus spp., Proteus mirabilis, Pseudomonas aeruginosa, Trueperella pyogenes e Mycobacterium tuberculosis (Rosa et al. 1989, Pignata et al. 2009, Benito-Peña et al. 2010, Ribeiro et al. 2011, Souza et al. 2011, Andrade et al. 2012, Valençoela et al. 2012, Higino et al. 2013).

Corynebacterium pseudotuberculosis, agente etiológico da LC é uma bactéria Gram-positiva, não esporulada, pleomórfica, aeróbica e parasita intracelular facultativa de macrófagos (Souza etal. 2011).Staphylococcus aureus são cocos Gram-positivos, coagulase e catalase positivos, hemolíticos, organizados em cachos de uva (Barbalho \& Mota 2001) que mais resistem no meio ambiente e causa abscessos em pequenos ruminantes (Souza et al. 2011). A Escherichia coli, pertencente à família Enterobacteriacea, bastonete Gram-negativo, não esporulado, facultativamente anaeróbia, que além de desencadear lesões abscedativas é responsável por mastite em ovinos e caprinos (Fagundes \& Oliveira 2004). Streptococcus spp. são cocos Gram-positivos, que formam pequenas ou longas cadeias, catalase negativos, aeróbios e anaeróbios facultativos (Barbalho \& Mota 2001). 0 Complexo Mycobacterium tuberculosis é formado por diversas espécies, dentre elas, Mycobacterium bovis, principal bactéria que desenvolve a tuberculose em mamíferos (Corner et al. 2011).

Os linfonodos mais atingidos por abscessos são os pré-escapulares, retrofaríngeos, parotídeos, sub-mandibulares e pré-crurais, provavelmente pela localização anatômica susceptível a ferimentos (Alves et al. 2007, Radostits et al. 2007). A macroscopia das lesões abscedativas na LC apresentam coloração que variam do branco ao amarelado e ou esverdeado, sem odor, consistência inicial pastosa e posteriormente, dura e seca com aspecto laminado (Radostits et al. 2007, Riet-Correa 2007, Fontaine \& Baird 2008). A histopatologia apresenta área de necrose central, formada por restos celulares e colônias bacterianas, circundada por uma faixa de infiltrado inflamatório composta por macrófagos epitelióides e neutrófilos degenerados. Presença de linfócitos e plasmócitos na região adjacente, delimitada por tecido conjuntivo fibroso (Fontaine \& Baird 2008, Souza et al. 2011).

O objetivo do presente trabalho foi determinar a prevalência, distribuição, identificação do agente etiológico e avaliação das lesões histológicas de abscessos frequentemente identificados e relacionados à linfadenite caseosa em ovinos e caprinos abatidos em um matadouro-frigorífico com Serviço de Inspeção Federal do estado da Bahia.

\section{MATERIAL E MÉTODOS}

Epidemiologia. A pesquisa foi realizada em um matadourofrigorífico do estado da Bahia especializado no abate de ovinos e caprinos, com Selo de Inspeção Federal (S.I.F.). No período de julho à dezembro de 2014 foram realizadas visitas e acompanhamento da inspeção de 404 caprinos e 744 ovinos, totalizando 1.148 animais. Os animais foram provenientes de 7 municípios do estado da Bahia, com idade entre 6 à 30 meses, de ambos os sexos. De acordo com a observação dos abscessos através de cortes em vísceras e linfonodos, foram capturados inquérito epidemiológico referente a procedência, espécie, idade, sexo e localização anatômica acometida. No período em estudo foi realizada a estimativa de perdas de órgãos e carcaças de ovinos e caprinos decorrente da condenação por lesões abscedativas.

Exame microbiológico. De um total de 1.148 pequenos ruminantes abatidos, foram coletadas 153 amostras de abscessos entre vísceras e linfonodos. Para o exame bacteriológico, as coletas foram realizadas com lâminas de bisturi estéreis, armazenadas em coletores universais estéreis e refrigeradas em caixa térmica. Logo em seguida foram encaminhadas ao laboratório para isolamento e identificação do agente etiológico. Inoculadas em tubos de ensaios contendo caldo Infusão Cérebro e Coração (BHI) e incubadas à $37^{\circ} \mathrm{C}$ em aerobiose por 24-72 horas. Após o crescimento que pôde ser verificado pela turvação do meio e com a formação de um precipitado no fundo do tubo de ensaio, o material foi semeado em meio Ágar Sangue Ovino a 5\% e incubadas por 24-72 horas. Após observado o crescimento de colônias foi realizada coloração de Gram. De acordo com a leitura do Gram as amostras foram semeadas em meios seletivos à $37^{\circ} \mathrm{C}$. As provas bioquímicas utilizadas foram: produção de catalase, coagulase, urease e indol; motilidade em ágar semi-sólido; cultivo em ágar citrato de Simmons; descarboxilação da lisina, ornitina e arginina; fermentação da lactose, sacarose e glicose; produção de gás e sulfeto de hidrogênio. Para a identificação da bactéria Escherichia coli, foi utilizado o Hicrome E. coli Ágar baseado em triptona Bile. Os micro-organismos etiológicos foram identificados de acordo o Manual of Clinical Microbiology (Murray et al. 1999).

Patologia. Para análise histopatológica, os fragmentos foram fixados em formol a $10 \%$ e processados de forma rotineira para histologia, emblocados em parafina, cortados a 5 micras de espessura, corados pela hematoxilina e eosina (HE). Adicionalmente em 21 casos, na qual não houve crescimento bacteriano foram submetidos a coloração especial de Ziehl-Neelsen para bacilos álcool ácidos resistentes.

\section{Epidemiologia}

\section{RESULTADOS}

Neste trabalho, foram identificadas lesões abscedativas nas espécies ovina e caprina em 13,3\% (153/1.148). A maior prevalência de lesões abscedativas ocorreu na espécie ovina com 73,85\% (113/153), em animais oriundos principalmente do município de Manoel Vitorino/BA (89/113), com faixa etária de 12 meses e machos. As lesões abscedativas na espécie caprina foi de $26,15 \%$ (40/153), principalmente em caprinos oriundos do município de Manoel Vitorino/BA (34/40), com idade entre 12-30 meses e mais em machos 7,17\% (29/404), do que em fêmeas 2,72\% (11/404) abatidas. A distribuição de lesões por espécie, procedência, idade e sexo apresentam-se no Quadro 1.

\section{Exame microbiológico}

Corynebacterium pseudotuberculosis foi o agente etiológico mais isolado das amostras em ambas as espécies. A localização das lesões em caprinos e ovinos foi identificada da seguinte maneira: Na espécie ovina, o fígado foi o local mais acometido por abscessos com $21,2 \%(24 / 113)$, seguido do linfonodo pré-escapular com 20,3\% (23/113). Em caprinos, os principais locais com lesões abscedativas foram os linfonodos retrofaríngeo 
Quadro 1. Distribuição das espécies por procedência, idade e sexo

\begin{tabular}{|c|c|c|c|c|}
\hline Espécie & Procedência & Quantidade & $\begin{array}{c}\text { Idade } \\
\text { (meses) } \\
\end{array}$ & Sexo \\
\hline \multirow[t]{4}{*}{ Caprina } & Manoel Vitorino $\left(14^{\circ} 08^{\prime} 42^{\prime \prime} \mathrm{S} 40^{\circ} 14^{\prime} 34^{\prime \prime} 0\right)$ & 34 & $12-30$ & $\mathrm{M} / \mathrm{F}$ \\
\hline & Ipirá (1209'28”S 3944'13”0) & 3 & 18 & M \\
\hline & Andorinha $\left(10^{\circ} 20^{\prime} 42^{\prime \prime S} 39^{\circ} 49^{\prime} 58^{\prime \prime} 0\right)$ & 2 & 30 & M \\
\hline & Ipecaetá (12¹8’00”S 39¹8’28”0) & 1 & 18 & M \\
\hline \multirow[t]{5}{*}{ Ovina } & Manoel Vitorino $\left(14^{\circ} 08^{\prime} 42^{\prime \prime} \mathrm{S} 40^{\circ} 14^{\prime} 34^{\prime \prime} 0\right)$ & 89 & $6-24$ & $\mathrm{M} / \mathrm{F}$ \\
\hline & Ipecaetá (12¹8’00”S 39¹8’28”0) & 12 & $12-24$ & $\mathrm{M} / \mathrm{F}$ \\
\hline & Euclides da Cunha $\left(10^{\circ} 30^{\prime} 28^{\prime \prime} \mathrm{S} 39^{\circ} 00^{\prime} 50^{\prime \prime} 0\right)$ & 6 & 18 & M \\
\hline & Antônio Cardoso (12²6’06”S 3907’12”0) & 4 & 12 & M \\
\hline & Santa Terezinha (1246’19”S 39³1'22”0) & 2 & 18 & $\mathrm{~F}$ \\
\hline TOTAL & & 153 & & \\
\hline
\end{tabular}

com 25\% (10/40) e linfonodos pré-escapular 25\% (10/40) (Quadros 2 e 3).

Nos exames microbiológicos, foram identificadas as seguintes bactérias: Corynebacterium pseudotuberculosis isolado de $33,33 \%(51 / 153)$ de abscessos em pequenos ruminantes, Escherichia coli em 19,61\% (30/153), Proteus mirabilis em 9,80\% (15/153), Pseudomonas aeruginosa em 7,19\% (11/153), Trueperella pyogenes em 5,22\% (8/153), Streptococcus spp. em 5,22\% (8/153) e Staphylococcus aureus em 4,57\% (7/153). Em 15,03\% (23/153), não houve crescimento bacteriano. Na Figura 1 é identificado a porcentagem dos agentes etiológicos cultivados e isolados em pequenos ruminantes.

\section{Patologia}

A macroscopia das lesões abscedativas foi caracterizada pela presença de material purulento ou caseoso que variava do branco-amarelado ao esverdeado, com ou sem odor, envoltos por cápsula fibrosa (Fig.2) e alguns com mineralização (Fig.3). Durante a avaliação histopatológica de 96 amostras, em 85,41\% observou-se a presença de cápsula de tecido conjuntivo fibroso com presença de infiltrado inflamatório moderado composto por linfócitos, macrófagos e plasmócitos (Fig.4). A presença de infiltrado inflamatório ao redor da área de necrose, formado por macrófagos e neutrófilos degenerados estiveram presentes em $89,58 \%$ das lesões. Em 14,58\% (14/96) das amostras houve identificação de macrófagos epitelióides e células gigantes. A área de necrose foi predominantemente caseosa, com evidenciação do agregado bacteriano (Fig.5) em 45,83\% (44/96) e mineralização foi observado em 48,95\% (47/96).

As alterações histológicas avaliadas de acordo com o micro-organismo isolado encontra-se no Quadro 4. Nas lesões histológicas descritas, não foram observados relação entre os diferentes micro-organismos isolados. Nas 21 amostras que não houve crescimento bacteriano, foram negativas na coloração de Ziehl-Neelsen para bacilos álcool ácidos resistentes.

\section{DISCUSSÃO}

A prevalência de lesões abscedativas apresentou-se maior na espécie ovina, com faixa etária de 6-30 meses e em machos. Deve-se considerar que no Brasil o rebanho de ovinos é maior que o de caprino, e o número de fêmeas abatidas no frigorífico foi menor que o de machos. A retenção de fêmeas é uma forma de garantir a reprodução, e assim aumentar a produção

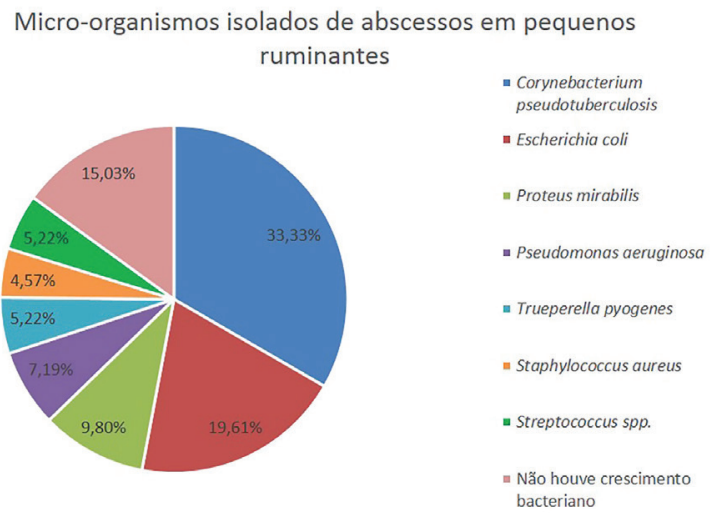

Fig.1. Agentes etiológicos cultivados e isolados em pequenos ruminantes.

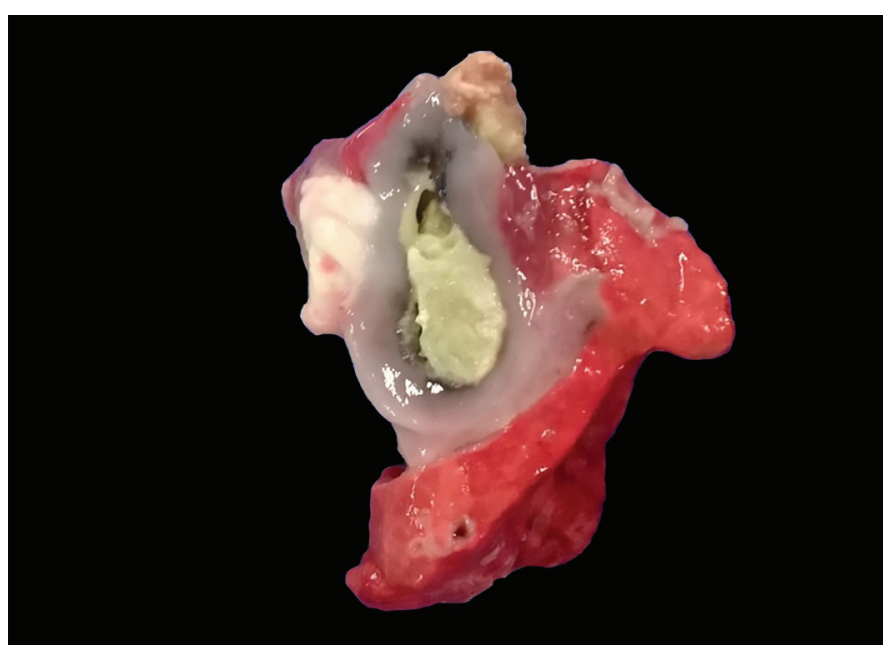

Fig.2. Abscesso pulmonar em ovino causado por Corynebacterium pseudotuberculosis. Observa-se material caseoso de consistência pastosa e envolvido por uma cápsula fibrosa.

(IMEA 2014), o que justifica o menor número de fêmeas, em determinados períodos, nos matadouros-frigoríficos.

Ao considerar a localização dos abscessos na espécie ovina, o fígado apresentou $21,2 \%$ e linfonodo pré-escapular 20,3\% 


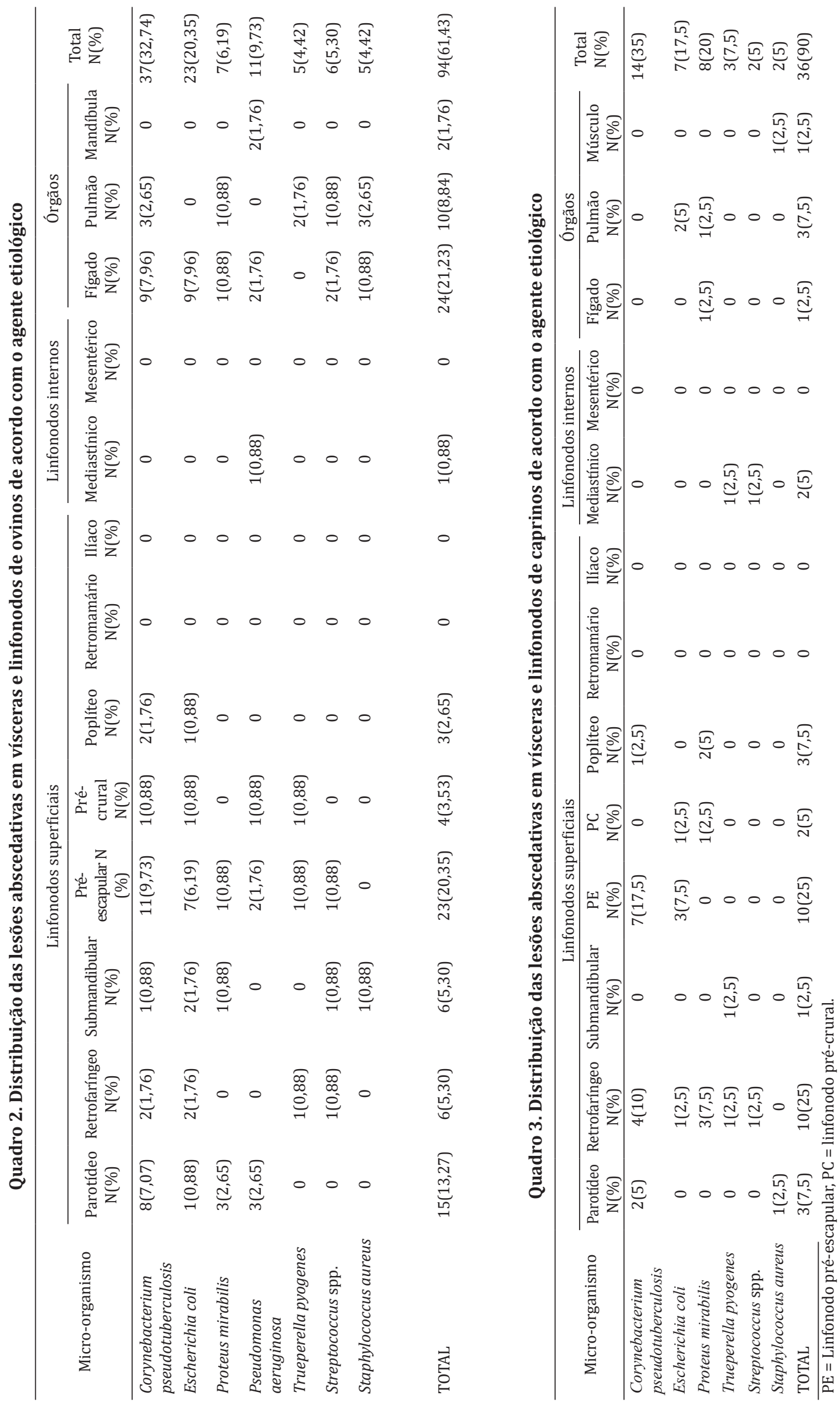




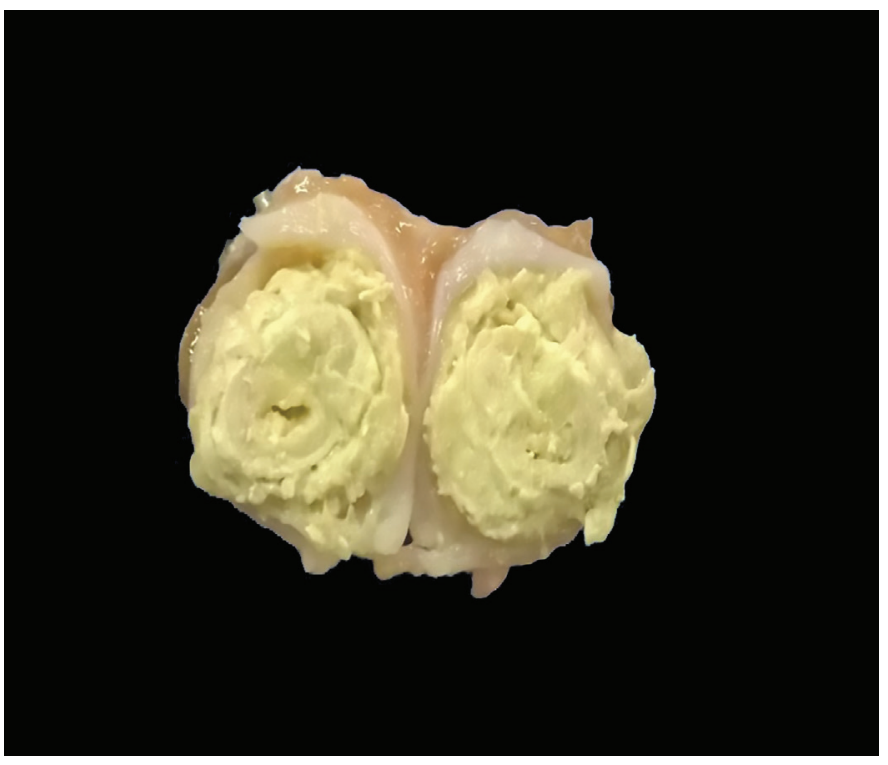

Fig.3. Lesão abscedativa em linfonodo pré-escapular de ovino, distribuída por toda região medular com lamelas concêntricas e mineralização, delimitado por cápsula. Isolamento e identificação de Trueperella pyogenes.

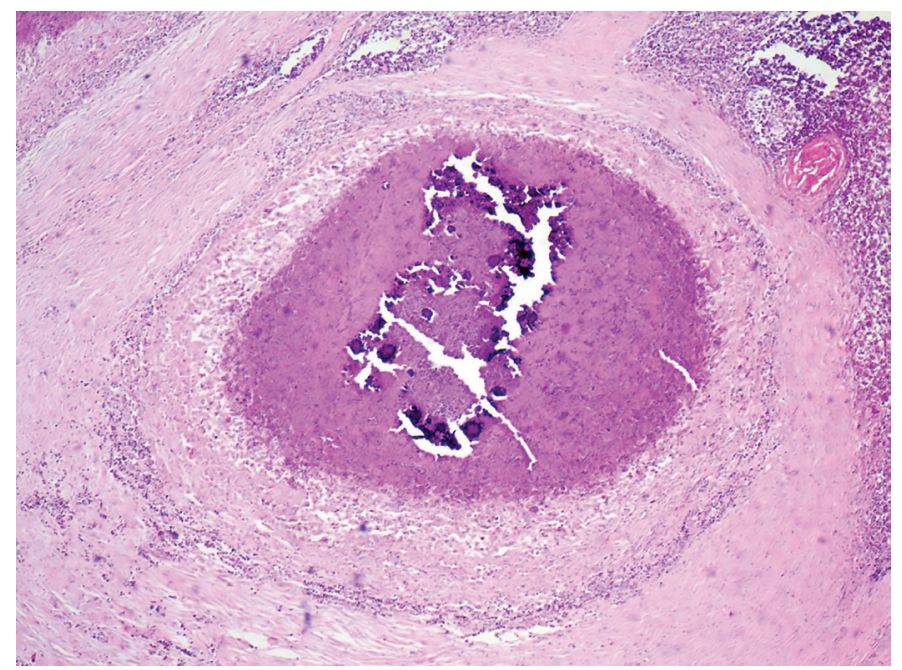

Fig.4. Lesão demonstrando em linfonodo de ovino centro caseoso formado por restos celulares e presença de mineralização. Ao redor, camada de infiltrado inflamatório envolvido por tecido conjuntivo fibroso. Isolamento e identificação de Escherichia coli. HE, obj.10x.

foram os órgãos mais acometidos, e a espécie caprina o linfonodo pré-escapular e retrofaríngeo foram os mais acometidos com $25 \%$. Estes resultados foram semelhantes às pesquisas de outros autores (Silva et al. 1982, Unanian et al. 1985, Souza et al. 2011, Andrade et al. 2012). Os abscessos hepáticos também podem ser consequência de uma onfaloflebite, na qual o processo inflamatório pode atingir as artérias umbilicais, a veia umbilical, o úraco ou os tecidos próximos ao umbigo. Por isso, pode provocar infecções no fígado, devido ao processo

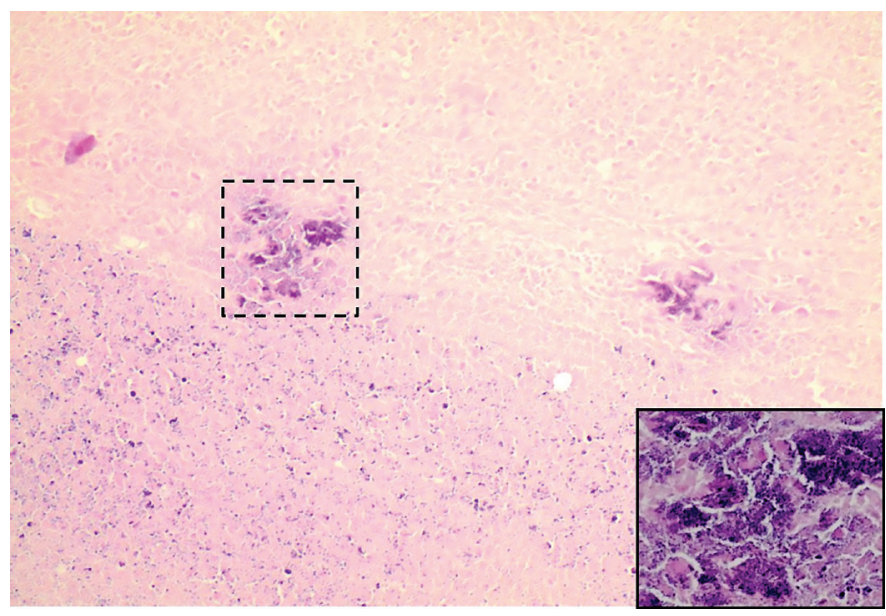

Fig.5. Agregado bacteriano em linfonodo de ovino (detalhe). Isolamento e identificação de Staphylococcus aureus. HE, obj.10x.

infeccioso estender-se pela veia umbilical com formação de um processo piogênico (Riet-Correa et al. 2011).

De acordo com Andrade et al. (2012), a maior frequência de abscessos causados por Corynebacterium pseudotuberculosis, foi na faixa etária de até 12 meses em ovinos e caprinos. Semelhante ao presente trabalho, que em ovinos a faixa etária acometida foi de 12 meses, porém diferente da espécie caprina em que a principal faixa etária acometida foi 30 meses.

A região Nordeste do Brasil apresenta como parte de sua flora natural diversas plantas cactáceas, que quando os animais entram em contato podem provocar erosões na pele e cavidade oral e facilitar a infecção por micro-organismos, dentre eles C. pseudotuberculosis (Unanian et al. 1985, Langenegger et al. 1991). Outros fatores importantes que podem estar relacionados são procedimentos cirúrgicos, quando não realizada assepsia correta, como em procedimentos de castração e caudectomia (Langenegger \& Langenegger 1988), além de confinamento e falta de controle sistemático nas fazendas, transporte e comercialização, o que possibilita a entrada de animais doentes no rebanho (Souza et al. 2011).

Neste trabalho, foram identificadas lesões abscedativas na espécie ovina e caprina em 13,3\% (153/1148). Dados próximos foram observados em um frigorífico do estado da Paraíba, na qual 15,9\% dos ovinos abatidos apresentaram abscessos em órgãos e linfonodos (Souza et al. 2011), e em outro estudo no mesmo estado, de 640 caprinos e ovinos examinados, 7,7\% apresentaram lesões macroscópicas de LC (Andrade et al. 2012). No presente estudo foram identificados sete espécies de bactérias das lesões abscedativas, sendo que os principais micro-organismos isolados tanto em ovino como em caprino foram C. pseudotuberculosis, Escherichia coli e Proteus mirabilis. Em trabalho de Souza et al. (2011), os principais agentes foram C. pseudotuberculosis, isolados em $74,5 \%$ das amostras, seguido de $S$. aureus com 7,8\% e E. coli com $2 \%$. Os micro-organismos identificados neste estudo, também foram observados em pesquisas anteriores em outros estados do Brasil (Rosa et al. 1989, Ribeiro et al. 2001, Benito-Peña et al. 2010, Andrade et al. 2012). Em outros estados do Brasil há registro de isolamento de Streptococcus spp. de 
Quadro 4. Avaliação das alterações histológicas relacionadas à presença dos micro-organismos identificados segundo a presença da lesão/número de amostras avaliadas

\begin{tabular}{|c|c|c|c|c|c|c|}
\hline \multirow[b]{2}{*}{ Micro-organismos } & \multicolumn{6}{|c|}{ Análise histopatológica } \\
\hline & $\begin{array}{c}\text { Presença de } \\
\text { cápsula } \\
\text { Presença/Número }\end{array}$ & $\begin{array}{l}\text { Infiltrado } \\
\text { Inflamatório } \\
\text { (cápsula) } \\
\text { P/N }\end{array}$ & $\begin{array}{c}\text { Infiltrado } \\
\text { Inflamatório ao } \\
\text { redor da área de } \\
\text { necrose } \\
\text { P/N }\end{array}$ & $\begin{array}{c}\text { Área de necrose } \\
\text { caseosa } \\
\mathrm{P} / \mathrm{N}\end{array}$ & $\begin{array}{c}\text { Evidenciação } \\
\text { do agregado } \\
\text { bacteriano } \\
\text { P/N }\end{array}$ & $\begin{array}{c}\text { Mineralização } \\
\text { P/N }\end{array}$ \\
\hline $\begin{array}{l}\text { Corynebacterium } \\
\text { pseudotuberculosis }\end{array}$ & $19 / 21$ & $19 / 21$ & $21 / 21$ & $21 / 21$ & $12 / 21$ & $12 / 21$ \\
\hline Escherichia coli & $12 / 16$ & $12 / 16$ & $15 / 16$ & $16 / 16$ & $7 / 16$ & $6 / 16$ \\
\hline Proteus mirabilis & $11 / 11$ & $11 / 11$ & $10 / 11$ & $10 / 11$ & $4 / 11$ & $7 / 11$ \\
\hline Pseudomonas aeruginosa & $11 / 11$ & $7 / 11$ & $10 / 11$ & $10 / 11$ & $6 / 11$ & $11 / 11$ \\
\hline Trueperella pyogenes & $7 / 8$ & $7 / 8$ & $6 / 8$ & $6 / 8$ & $4 / 8$ & $2 / 8$ \\
\hline Streptococcus spp. & $4 / 6$ & $4 / 6$ & $4 / 6$ & $4 / 6$ & $4 / 6$ & $2 / 6$ \\
\hline S. aureus & $5 / 6$ & $5 / 6$ & $6 / 6$ & $6 / 6$ & $1 / 6$ & $0 / 6$ \\
\hline $\begin{array}{l}\text { Ausência de isolamento } \\
\text { bacteriano }\end{array}$ & $13 / 17$ & $13 / 17$ & $12 / 17$ & $9 / 17$ & $8 / 17$ & $6 / 17$ \\
\hline
\end{tabular}

lesões abscedativas, especialmente de linfonodos em pequenos ruminantes (Unanian et al. 1985, Ribeiro et al. 2011).

Já em um estudo realizado na Espanha, de lesões abscedativas em ovinos, em 71\% dos abscessos foram isolados $S$. aureus (De La Fuente et al. 1997) e no Canadá a prevalência de carcaças condenadas por LC de ovinos abatidos, em $24 \%$ o micro-organismo isolado foi o $S$. aureus (Arsenault et al. 2003).

A macroscopia da LC é caracterizada por abscessos geralmente com conteúdo de coloração que varia do branco ao amarelado e ou esverdeado, sem odor e com consistência inicial pastosa que finalmente se torna dura e seca com uma aparência laminada (Radostits et al. 2007, Riet-Correa 2007, Fontaine \& Baird 2008).

Ao considerar as bactérias isoladas, as características avaliadas foram observadas na maioria das amostras submetidas. Em 44/96 amostras foi possível evidenciar agregados bacterianos, segundo Souza et al. (2011) essa alteração também foi identificada em 23 de 39 linfonodos. No presente trabalho essa característica esteve presente em 47/96 das amostras avaliadas e causadas por C. pseudotuberculosis, E. coli, P. mirabilis, Pseudomonas aeruginosa, Trueperella pyogenes e Streptococcus spp. A mineralização e células gigantes são lesões, principalmente encontradas na tuberculose e LC (Pignata et al. 2009, Souza et al. 2011), sendo que nesta pesquisa foi possível identificar essas alterações nas amostras que foram isoladas E. coli, P. mirabilis, P. aeruginosa, Arcanobacterium pyogenes e Streptococcus spp. As lesões causadas por $S$. aureus não foi observado mineralização. Segundo Souza et al. (2011), amostras que foram isoladas C. pseudotuberculosis, em 97,4\% apresentaram mineralização, $59 \%$ foi observado grandes colônias e presença de células gigantes em $53,8 \%$. Nos abscessos que foram isolados Staphylococcus spp., as lesões histológicas foram muito semelhantes quando comparados aos que tiveram crescimento de $C$. pseudotuberculosis.

As lesões por LC são causa significativa de condenações de carcaças inspecionadas e, segundo Radostits et al. (2007), o índice de condenação por LC é de 3 a $5 \%$ para as carcaças de ovinos adultos. No estado do Rio Grande do Sul, a prevalência da enfermidade foi de 8,0\% em ovelhas e 1,53\% em capões (Silva et al.1982). Na Paraíba 15,9\% dos ovinos abatidos em frigorífico apresentaram lesões macroscópicas sugestivas de LC, dentre os lotes abatidos no estudo.

\section{CONCLUSÕES}

A prevalência de lesões abscedativas na espécie ovina e caprina foi maior em machos. As lesões macroscópicas e histológicas dos abscessos coletados, não apresentaram diferenças entre micro-organismos isolados.

Conforme resultados alcançados na avaliação microbiológica das amostras provenientes do frigorífico, somente 33,3\% correspondeu à LC causada por lesões de Corynebacterium pseudotuberculosis, e em 66,7\% a causa dos abscessos foram outras bactérias; por isso deve-se considerar a possibilidade de infecções com agentes etiológicos diferente em lesões abscedativas.

Dessa forma, a determinação do agente etiológico em abscessos nos pequenos ruminantes é uma medida adequada para correta aplicação dos métodos sanitários de controle e profilaxia nos rebanhos ovinos e caprinos.

Agradecimentos.- Ao Serviço de Inspeção Federal MAPA/BA, aos profissionais do matadouro-frigorífico, à equipe dos Laboratórios e a Fundação de Amparo à Pesquisa do estado da Bahia (FAPESB) pela concessão da bolsa do primeiro autor.

\section{REFERÊNCIAS}

Abreu S.R.O., Mota R.A., Pinheiro Júnior J.W., Rosinha G.M.S. \& Castro R.S. 2008. Perfil de sensibilidade antimicrobiana in vitro de isolados de Corynebacterium pseudotuberculosis de caprinos e ovinos com linfadenite caseosa no sertão de Pernambuco, Brasil. Vet. Zootec. 15(3):502-509.

Alves F.S.F., Santiago L.B. \& Pinheiro R.R. 2007. Linfadenite Caseosa: o estado da arte. Documentos, Embrapa Caprinos, Sobral. 60p.

Andrade J.S.L., Azevedo S.S., Teles J.A.A., Higino S.S.S. \& Azevedo E.O. 2012. Ocorrência e fatores de risco associados à infecção por Corynebacterium pseudotuberculosis em caprinos e ovinos do semiárido paraibano. 
Pesq. Vet. Bras. 32(2):116-120. <http://dx.doi.org/10.1590/S0100736X2012000200004>

Arsenault J., Girard C., Dubreuil P., Daignault D., Simard C. \& Bélanger D. 2003. Prevalence of and carcass condemnation from maedi-visna, paratuberculosis and caseous lymphadenitis in culled sheep from Quebec, Canada. Prevent. Vet. Med. 59(1/2):67-81.

Barbalho T.C.F. \& Mota R.A. 2001. Isolamento de agentes bacterianos envolvidos em mastite subclínica bovina no estado de Pernambuco. Revta Bras. Saúde Prod. Anim. 2(2):31-36

Benito-Peña A., Peris B., Aduriz G., Martinez J. \& Corpa J.M. 2010. Purulent nasomaxillary and mandibular osteomyelitis in sheep caused by Pseudomonas aeruginosa. Vet. Rec. 166(4):115-116. <http://dx.doi.org/10.1136/ vr.b4784><PMid:20097891>

Corner L.A.L., Murphy D. \& Gormley E. 2011. Mycobacterium bovis infection in the Eurasian badger (Meles meles): the disease, pathogenesis, epidemiology and control. J. Comp. Pathol. 144(1):1-24. <http://dx.doi.org/10.1016/j. jcpa.2010.10.003><PMid:21131004>

De La Fuente R., Cid D., Sanz R. \& Ruiz-Santa-Quiteria J.A. 1997. An outbreak of abscess disease associated with shearing. Small Rum. Res. 26:283-286.

Fagundes H. \& Oliveira C.A.F. 2004. Infecções intramamárias causadas por Staphylococcus aureus e suas implicações em saúde pública. Ciência Rural 34(4):1315-1320.<http://dx.doi.org/10.1590/S0103-84782004000400058>

Fontaine M.C. \& Baird G.J. 2008. Caseous lymphadenitis. Small Rum. Res. 76(1/2):42-48. <http://dx.doi.org/10.1016/j.smallrumres.2007.12.025>

Gouveia A.M.G. 2003. Aspectos sanitários da caprinovinocultura no Brasil. Anais Simpósio Internacional de Caprinos e Ovinos de Corte, João Pessoa, PB. (CD-ROM)

Guedes K.M.R., Riet-Correa F., Dantas A.F.M., Simões S.V.D., Miranda Neto E.G., Nobre V.M.T. \& Medeiros R.M.T. 2007. Doenças do sistema nervoso central em caprinos e ovinos no semi-árido. Pesq. Vet. Bras. 27(1):29-38. <http://dx.doi.org/10.1590/S0100-736X2007000100006>

Higino S.S.S., Pinheiro S.R., Rocha V.C.M., Souza G.O., Portela R.A., Alves C.J., Vasconcellos S.A., Dib C.C., Rosário T.R., Melville P.A. \& Azevedo S.S. 2013. Tuberculose em caprinos e ovinos abatidos no semiárido da Paraíba, Brasil. Pesq. Vet. Bras. 80(3):281-287.

IMEA 2014. Perspectivas de Curto Prazo para o Rebanho de Machos em MT. Instituto Mato-Grossense de Economia Agropecuária, Cuiabá. Disponível em <www.imea.com.br/.../E061_Relatorio_Perspectiva_machos_2014. pdf $>$ Acesso em 3 mar. 2016.

Langenegger J. \& Langenegger C.H. 1988. Reprodução da linfadenite caseosa em caprinos com pequeno número de Corynebacterium pseudotuberculosis. Pesq. Vet. Bras. 8:23-26.

Langenegger J., Langenegger C.H. \& Scherer P.O. 1991. Prevalência e diagnóstico comparativo da linfadenite caseosa em caprinos do Estado do Rio de Janeiro. Pesq. Vet. Bras. 11:31-34.
Murray P.R., Baron E.J., Pfaller M.A., Tenover F.C. \& Yolken R.H. 1999. Manual of Clinical Microbiology. 7th ed. American Society for Microbiology, Washington, DC. 485p.

Pignata W.A., Alves C.J., Azevedo S.S., Dantas A.F.M., Gomes A.A.B., Remígio F.R., Lima F.S. \& Mota P.M.P. 2009. Prevalência para tuberculose caprina no semi-árido paraibano. Pesq. Vet. Bras. 29(7):526-532.<http://dx.doi. org/10.1590/S0100-736X2009000700006>

Radostits O.M., Gay C.C., Hinchcliff K.W. \& Constable P.D. 2007. Veterinary Medicine: a Textbook of the Diseases of Cattle, Horses, Sheep, Pigs and Goats. 10th ed. Saunders Elsevier, Philadelphia, p.795-798.

Ribeiro M.G., Dias Júnior J.G., Paes A.C., Barbosa P.G., Nardi Júnior G. \& Listoni F.J.P. 2001. Punção aspirativa com agulha fina no diagnóstico do Corynebacterium pseudotuberculosis na linfadenite caseosa caprina. Arqs Inst. Biológico, São Paulo, 68(1):23-28.

Ribeiro M.G., Belotta A.F., Fernandes M.C., Guena R., Nardi Júnior G., Lara G.H.B., Giuffrida R. \& Zamprogna T.0. 2011. Citologia aspirativa no diagnóstico da linfadenite em ovinos. Pesq. Vet. Bras. 31(10):839-843. <http://dx.doi. org/10.1590/S0100-736X2011001000002>

Riet-Correa F. 2007. Linfadenite caseosa, p.347-352. In: Riet-Correa F., Schild A.L., Lemos R.A.A. \& Borges J.R.J. (Eds), Doenças de Ruminantes e Equídeos. Vol.1. 3a ed. Pallotti, Santa Maria. 694p.

Riet-Correa F., Simões S.V.D. \& Azevedo E.O. 2011. Principais enfermidades de caprinos e ovinos no Semiárido Brasileiro. Anais Congresso Latinoamericano de Buiatria, Paysandú, Uruguay. (Resumo)

Rosa J.S., Johnson E.H., Alves F.S.F. \& Santos L.F.L. 1989. Ocorrência de abscesso hepático em caprinos. Pesq. Agropec. Bras. 24(1):63-68.

Santos R.L. 2001. Diagnóstico da cadeia produtiva da caprinocultura de corte no Estado da Bahia. Monografia, Faculdade São Francisco de Barreiras, Barreiras, BA. 40p.

Silva S.F., Silva A.F., Lauzer J.J. \& Costa D.F. 1982. Linfadenite caseosa em ovinos abatidos na região da Campanha do Rio Grande do Sul. Anais Congresso Brasileiro de Medicina Veterinária, Camboriú, SC, p.50.

Souza M.F., Carvalho A.Q., Garino Junior F. \& Riet-Correa F. 2011. Linfadenite caseosa em ovinos deslanados abatidos em um frigorífico da Paraíba. Pesq. Vet. Bras. 31(3):224-230. <http://dx.doi.org/10.1590/S0100736X2011000300007>

Unanian M.M., Silva A.E.D.F. \& Pant P. 1985. Abscesses and caseous lymphadenitis in goats in tropical semi-arid north-east Brazil. Trop. Anim. Health Prod. 17(1):57-62. <http://dx.doi.org/10.1007/BF02356137><PMid:3992674>

Valençoela R.A., Rodrigues F.S., Rodrigues O.A., Guimarães E.B. \& Leal C.R.B. 2012. Estudo bacteriológico e histológico de abscessos em ovinos abatidos em Campo Grande, Mato Grosso do Sul. Vet. Foco 9(2):158-163. 